\title{
Deviant Sexual Behaviours amongst Substance Abusers - a clinical study
}

\author{
Sheetal Bidkar ${ }^{1}$, Anuj Khandelwal², Sonal Jhalani ${ }^{3}$ \\ ${ }^{1}$ Clinical Psychologist, Suasth One Step Clinic, Mumbai. \\ ${ }^{2}$ Consultant Psychiatrist, Kiran Multi Super Speciality Hospital and Research Centre, Surat \\ ${ }^{3}$ Consultant Psychiatrist, Shalby Multispeciality Hospital, Surat \\ Corresponding author: Sonal Jhalani \\ Email-drajkl@yahoo.com
}

\begin{abstract}
This paper looks at a qualitative review and concept map approach of deviant sexual behavior in patients with substance abuse. 8 cases are analyzed and presented in a clinically relevant format.
\end{abstract}

Keywords: sexually deviant behavior, substance abuse.

(Paper received $-18^{\text {th }}$ March 2018, Peer review completed $-19^{\text {th }}$ May 2018)

(Accepted - 24 $4^{\text {th }}$ June 2018)

\section{INTRODUCTION}

Substance addiction is referred as a family disease, because it not only affects the user but also the family. Neglecting partner \& children needs, poor sexual performances, apathetic view and preoccupation with alcohol or drugs worsens the family life as a whole. The maladaptive emotions \& behaviours eventually can be seen in other family members too [1-3].

\section{High Risk Sexual Behaviors (HRSB) \& Substance Abuse (SA)}

A range of psychiatric disorders including the high risk sexual behaviors (HRSB) have been associated with SA in literature. Involvement in HRSB and SA has been the prime focus in many studies in the past as these are important public health concerns. The association of HRSB with substance use has been shown to increase with problem use rather than any use [4-5]. Substance use is not the only one but one among a number of factors involved in determining the riskiness of a sexual encounter [6]. HRSB includes acts such as indulging in multiple sexual partners, unprotected sexual intercourse [7], having sex while under substance intoxication, having sex with a stranger/new partner [8] or unplanned sex [9].

Heavy alcohol use has been shown to influence the decision-making of an individual by making choice for riskier patterns. This is attributable to disinhibition and lowering of risk perception under influence of alcohol [10]. Also, once a sexual encounter begins, alcohol causes decrease in safe sex behaviors like reduction in the likelihood of using condoms or other methods of contraception [11-12]. Similar results have been noticed with other illicit drug use as well [13-14]. Thus, the individuals who drink more heavily or take more amount of illicit drugs are at greater risk for adverse outcomes such as sexually transmitted diseases [15-16] and unwanted pregnancy [17]. Casual sex and to have multiple partners have been associated in literature to frequent \& heavy alcohol users [18-20]. However the relationship between alcohol use and condom use during sex is a complex \& tricky one to observe [21]. Sexual encounters while under alcohol intoxication and not the drinking frequency of alcohol, has been observed linked to unprotected sex. Alcohol Intoxication 
in a sexual situation indicates underlying personality factors such as sensation seeking making a person indulge in risky sex [22-24]. Other illicit drug use regardless of the alcohol drinking frequency confers an additional risk for HRSB, particularly when used in sexual situations. Also illicit drug use has been found significantly predictive of continuing with HRSB. Thus the individuals who use drugs and alcohol in sexual situations are at a greater risk for HRSB [25]. One of the possible explanations for the association between alcohol and high-risk sexual behavior is that drinking heavily may be a part of a larger spectrum of high-risk behaviors [26]. The Nation-wide behavior surveillance survey was carried out by the National AIDS Control Organization (NACO) in 2002 among the clients of female sex workers in India. This survey reported nearly $75 \%$ of respondents ever having alcohol [27]. Thus, integrating the interventions for sex risk behaviors and substance use becomes important and can be a reasonably good strategy [28].

Research has consistently demonstrated several common risk factors for HRSB as well as substance abuse spanning across the Adverse Childhood Experiences (ACEs), family, peer and socio-economic domains. These factors display interplay between - sensation seeking, externalizing problems, deviant peer affiliation, low socio-economic status and low parental monitoring [29-31]. But what remains the under-researched, naïve, untouched grey area requiring inquiry is the association of substance abuse (SA) and deviant sexual behaviors (DSB) in Indian population. Therefore, to fill this substantial gap in literature we took an initiative to come up with our study findings in this research paper.

\section{Deviant Sexual Behavior (DSB) \& Substance Abuse (SA)}

Sexual Deviance is a tricky \& complex topic to discuss because both conformity and deviance carry no absolute meanings rather are relative terms which changes as per the different societal cultures and also with time when we talk about one particular culture at different timelines. DSBs also known as paraphilias are the sexual acts which as per the societal norms are abnormal [32]. These sexual behaviors stand atypical when defined in current moral, legal or medical terms. The process of socialization along with moral and religious more in any society moderates the sexual behaviors of its people. Over the last few decades many of the western societies have shed their inhibitions in the expression of sexuality making acts like masturbation (alone or in company), anal and/or oral sex among mutually consenting adults (for expression of love and getting pleasure) as acceptable considering them as typical sexual behaviors [33]. But these are still considered deviant in many of other countries including India [34].

The sexual acts considered as DSBs differ from country to country depending upon the culture they follow. As per the Indian societal norms, Normal Sex, is defined as penile-vaginal intercourse with procreation the attached necessary meaning to it [35]. Thus, in the current study we have considered all sexual acts other than penile-vaginal intercourse under a common umbrella term DSB.

Thus, the spectrum of DSB encompasses-

Multi partner relationship: Since a few decades with rapid globalization there has been a substantial change seen in the heterosexual behavior of people in India. This is characterized by an early age at first intercourse which ultimately results in lengthening of the period of persistent or recurrent changes in sexual partners [36-37].

Forced/Involuntary Abstinence (Involuntary celibacy): Persistent or recurrent abstinence from all sexual contacts cause significant interpersonal problems and marked distress. It differs from conscious abstinence when observed for internal attitudes and belief system of the person [38-40].

Participation in pornography: Participation in sexual activity involving video recording of self [41].

Watching pornography: Persistent or recurrent use of pornography material to experience sexual excitement and orgasm [42-45].

Exhibitionism: Persistent, recurrent \& disinhibited exposing behavior characterised by exposure of one's genitalia to an unsuspecting stranger for sexual arousal which is followed by achieving orgasm through masturbation [46]. This also includes self-disclosure of private parts on technology instruments using internet [47].

We came across a very sparse amount of literature over this topic and thus not much on the association of DSB and SA can be quoted. In one of the research papers, 97 male substance addict subjects in an in-patient care facility in New Zealand were studied. DSB were seen in a high proportion of these subjects [48]. 


\section{Indian Culture \& DSB in Addicts}

Indian culture provides a unique research setting as it places strong emphasis over social bonds and strong social control over individuals. While this strong social network has a lot many positive aspects, it can also have deleterious effects and negative outcomes, such as delay in taking medical help due to stigma attached to the condition and thus a fear of social exclusion. Thus, this could lead to a decrease in the likelihood of reporting substance related problems in addicts especially the DSB which in its own meaning is treated as a taboo to talk about. Thus, addicts may keep these as secrets within themselves which may contribute to increase these problem behaviors further [49]. However, this doesn't mean that we expect DSBs to be a common response to the negative emotions in all addicts in India as there exists a high level of social control in Indian society.

Historically India is the first country where sex has been treated as a science and numerous volumes have been written in past educating about sex through means of art [50]. Although India pioneered in this field but still we lack the spread of sexual education among common people in India. Although intuitively everyone understands that the people with substance use disorder may have DSBs, but literature lacks the precise description of these behaviors in Indian context and thus it gets necessary to precisely describe them using a scientific method. Answering the question taking gender-based differences into account is also important to establish the unique preventive and treatment approaches.

\section{Contributions of this study}

This study provides with some valuable contributions to the current literature. Some of the classic examples of DSBs among substance abusers in Indian context are presented aiming to throw some light on the factors involved in dynamic interplay between SA and DSB. We expect that thinking errors, disinhibition \& extreme impulsive emotional responses have mediating roles between SA and DSBs. Addicts may in turn use their body and DSBs as a source to continue \& support addiction. Literature supports trading sex by substance addicts to support their addiction [51].

Secondly the gender based differences in expression of DSBs among addicts will be explored. We expect the socially constructed gender norms \& expectations for Indian females to differentiate their responses to the negative emotions stemming up from substance abuse.

Finally, we will enquire about the sexual deviance, if any, in the life partner of addict.

\section{METHODOLOGY}

A qualitative exploratory model is used to study all the clinical cases $(n=8)$ admitted for over 2 months period in the Deaddiction-Rehabilitation-Counselling Center in Andhra Pradesh for treatment. All cases were screened for self-report of DSB in the preceding two years. The cases were identified and studied considering review literature on the topic. During their stay the patients were evaluated and data was obtained and noted through a semi-structured interview by a psychiatrist and a psychologist. DSBs in this study were defined as forced abstinence, multi partner relationship, participation in pornography, watching pornography, lack of desire/diminished libido, obsessive self- gratification, and exhibitionism. Few of these behavior patterns can be categorized as sexual dysfunctions but few patterns are unhealthy sexual practices. Patients with no substance abuse and those with mental retardation were excluded. This was done so as to avoid the effects of intellectual impairment on addiction screening test. All subjects underwent a detailed semi structured interview to elicit DSB. An informed consent was obtained from all the patients and confidentiality was assured prior to starting the interview.

1. Semi structured interview to assess addiction and related damages: Developed for the purpose of assessment of severity of substance use and the ill effects faced by the subject.

2. Semi structured interview to assess DSB and contributory factors: Developed for the purpose of assessing the contributory factors for DSB and to assess the nature of the DSBs. Subject's perception and attitude towards the DSBs were also assessed. 


\section{Analysis}

Since decades researchers in various fields have been creating new knowledge using the concept map tool [52-55] and thus we evaluated our cases using concept mapping. Concept map tool forms a powerful method to represent and archive knowledge, create new knowledge about the topic being explored and find the gaps in the collected knowledge structure [56-59]. Concept maps were utilized to graphically represent and analyze events in context of DSBs among addicts.

\section{RESULTS}

A 56 years old female married to the patient who was Toddy addict - Involuntary celibacy in spouse of substance addict

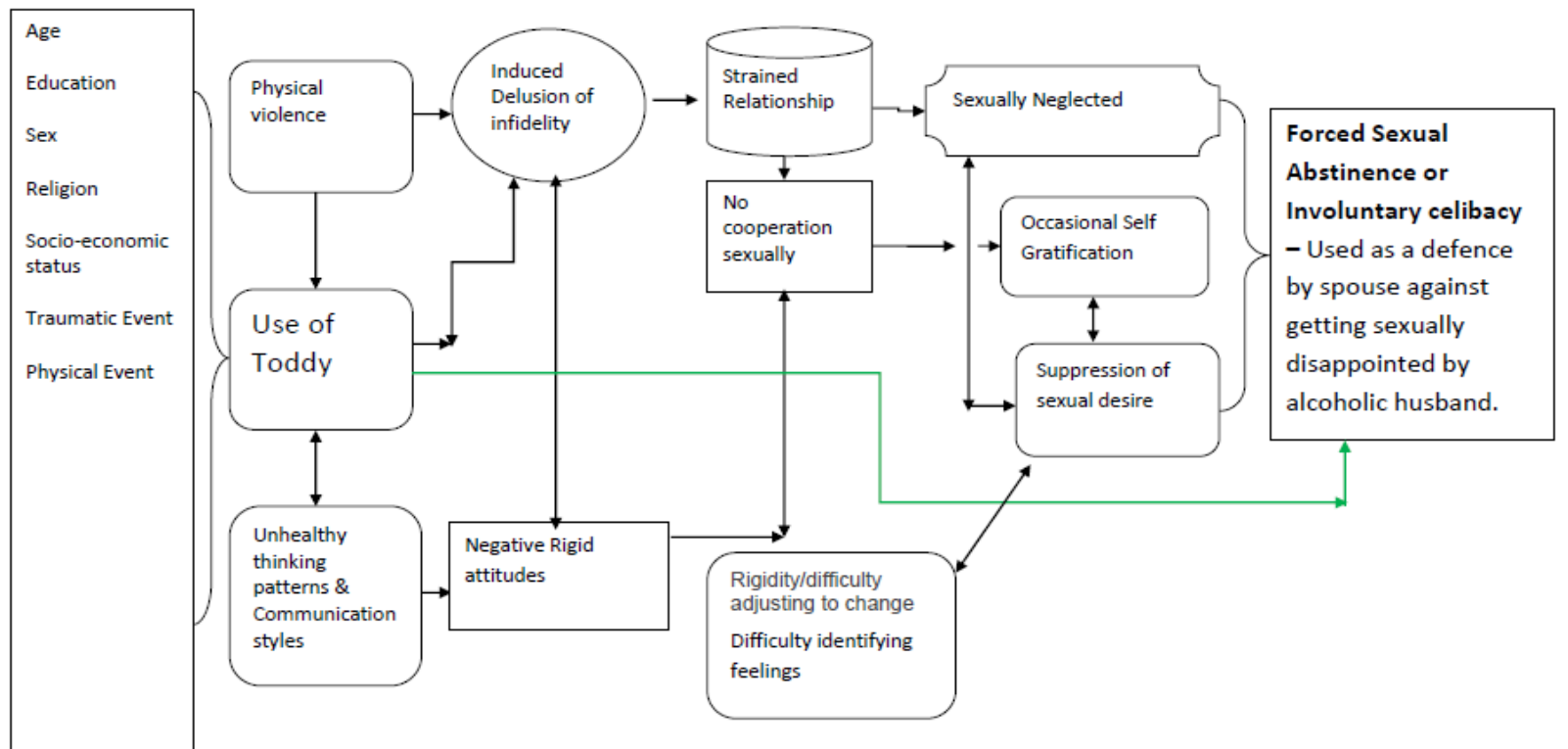

20 years old male patient B with poly substance addiction - Multiple Partner Relationship
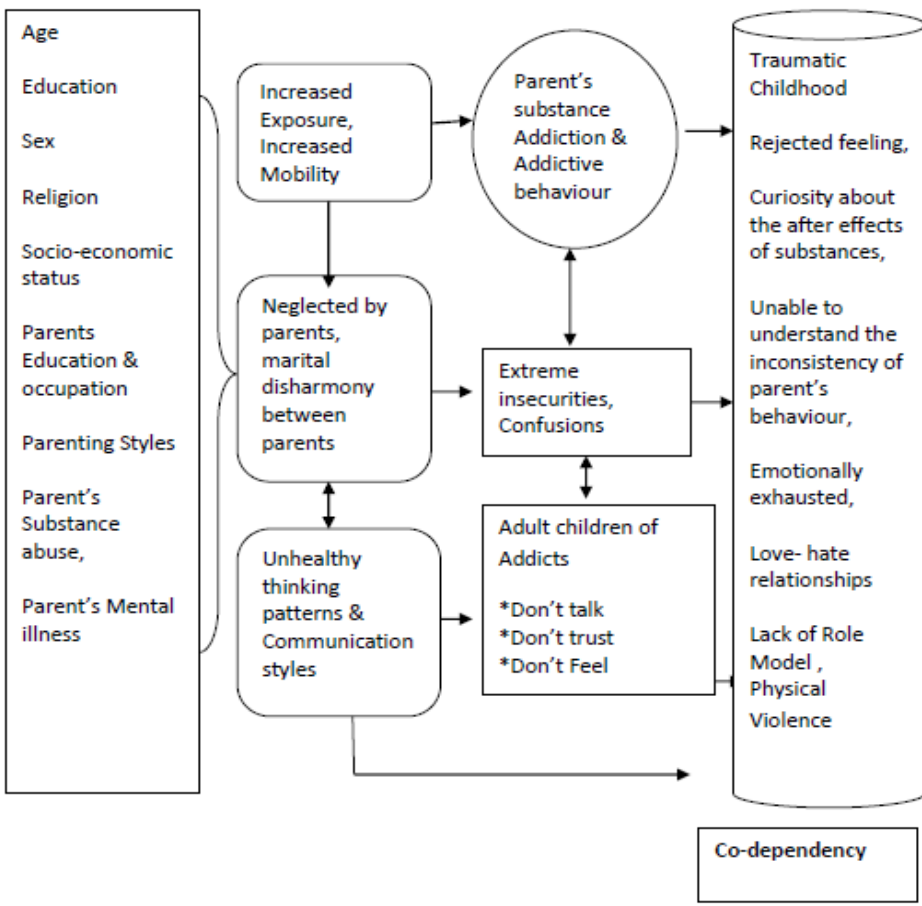

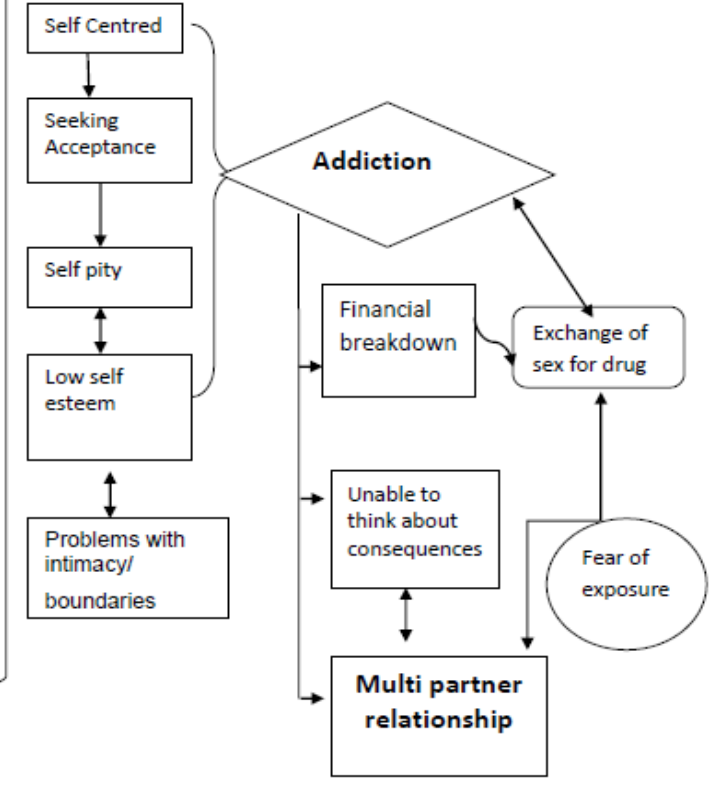


35 years old male patient $\mathrm{C}$ with Alcohol addiction - Multiple Partner Relationship including Homosexual Activity

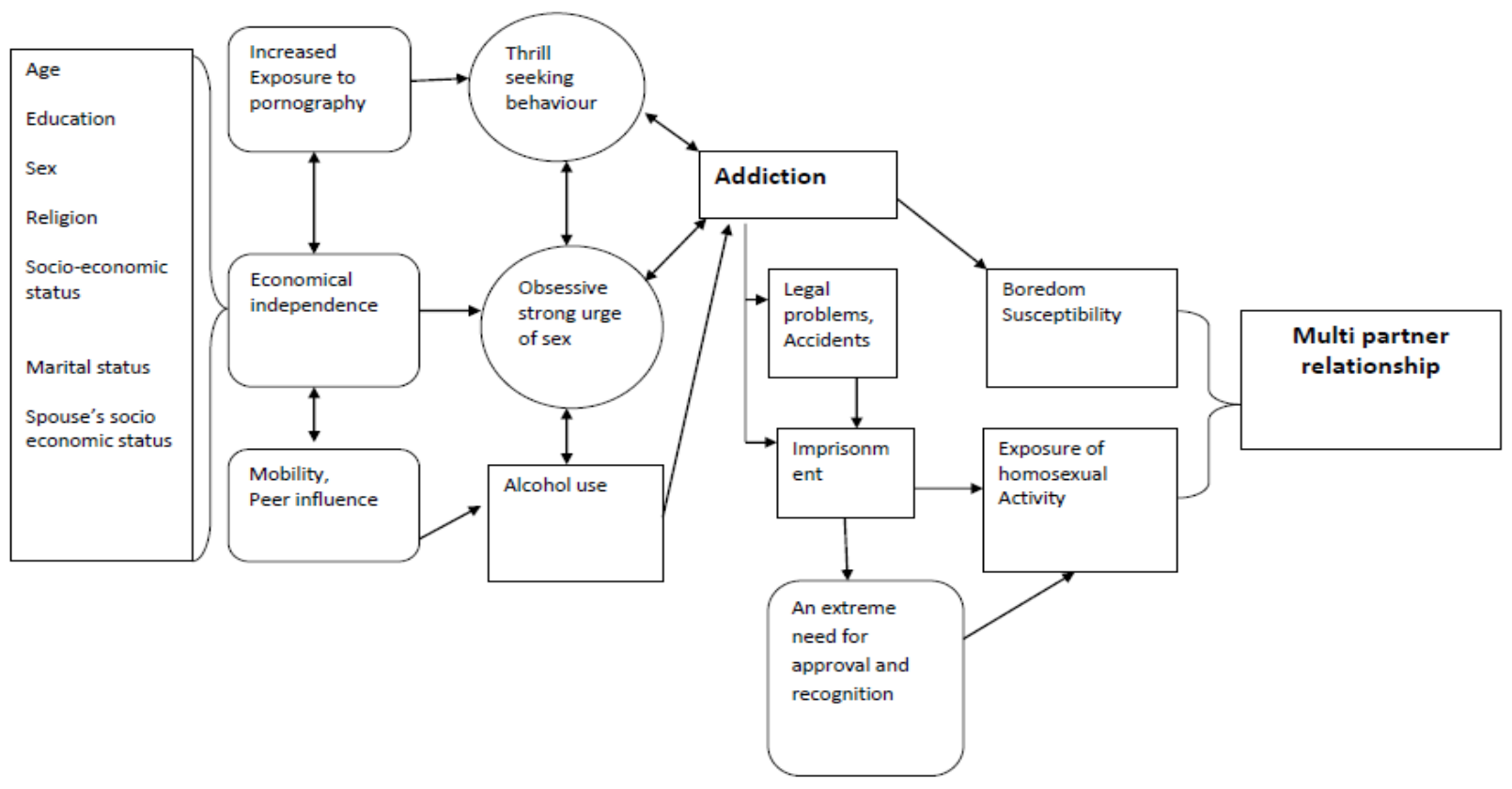

29 year old female patient D with polysubstance use disorder - Multiple Partner Relationship, Watching \& Participating in Pornography

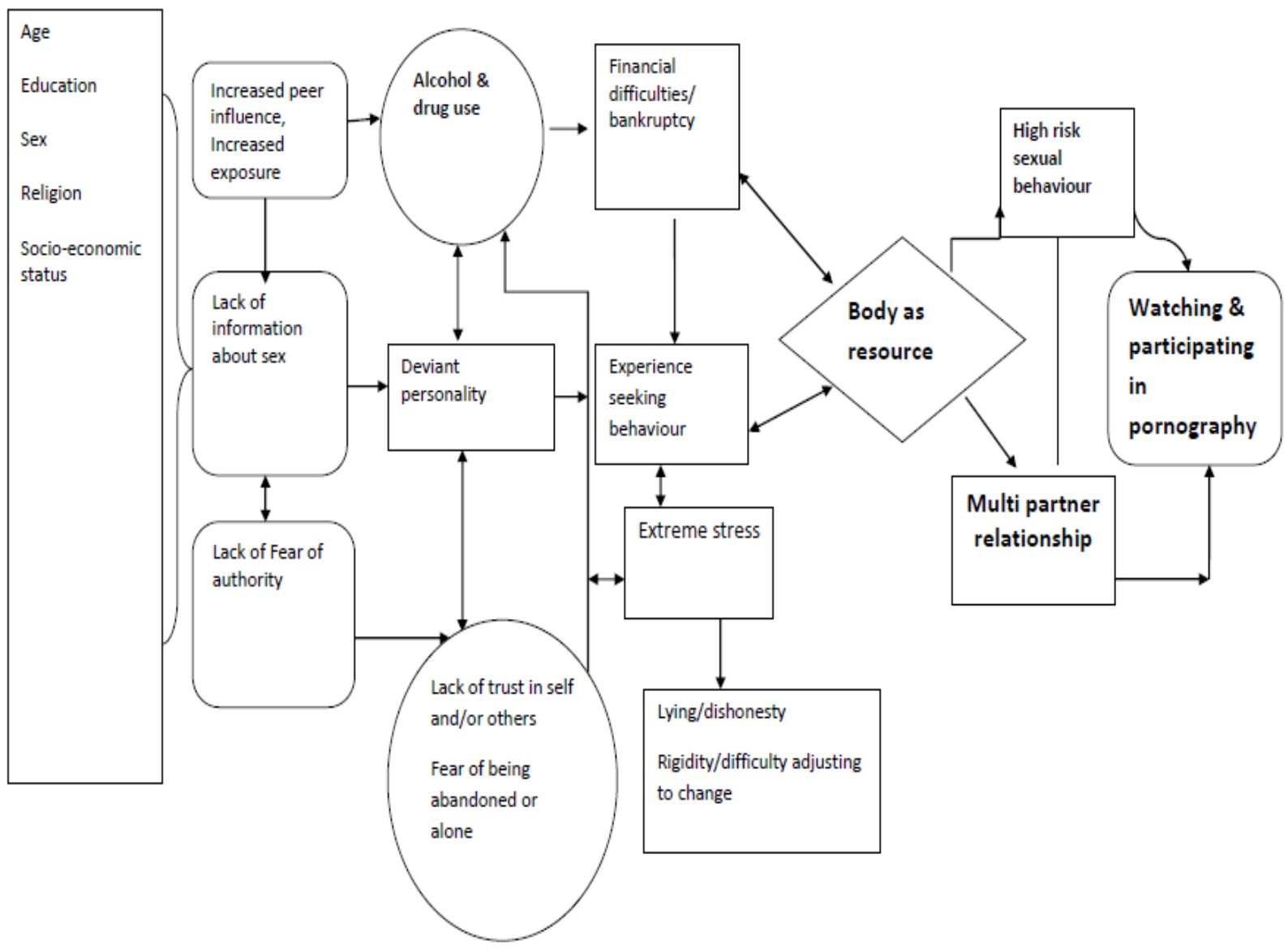




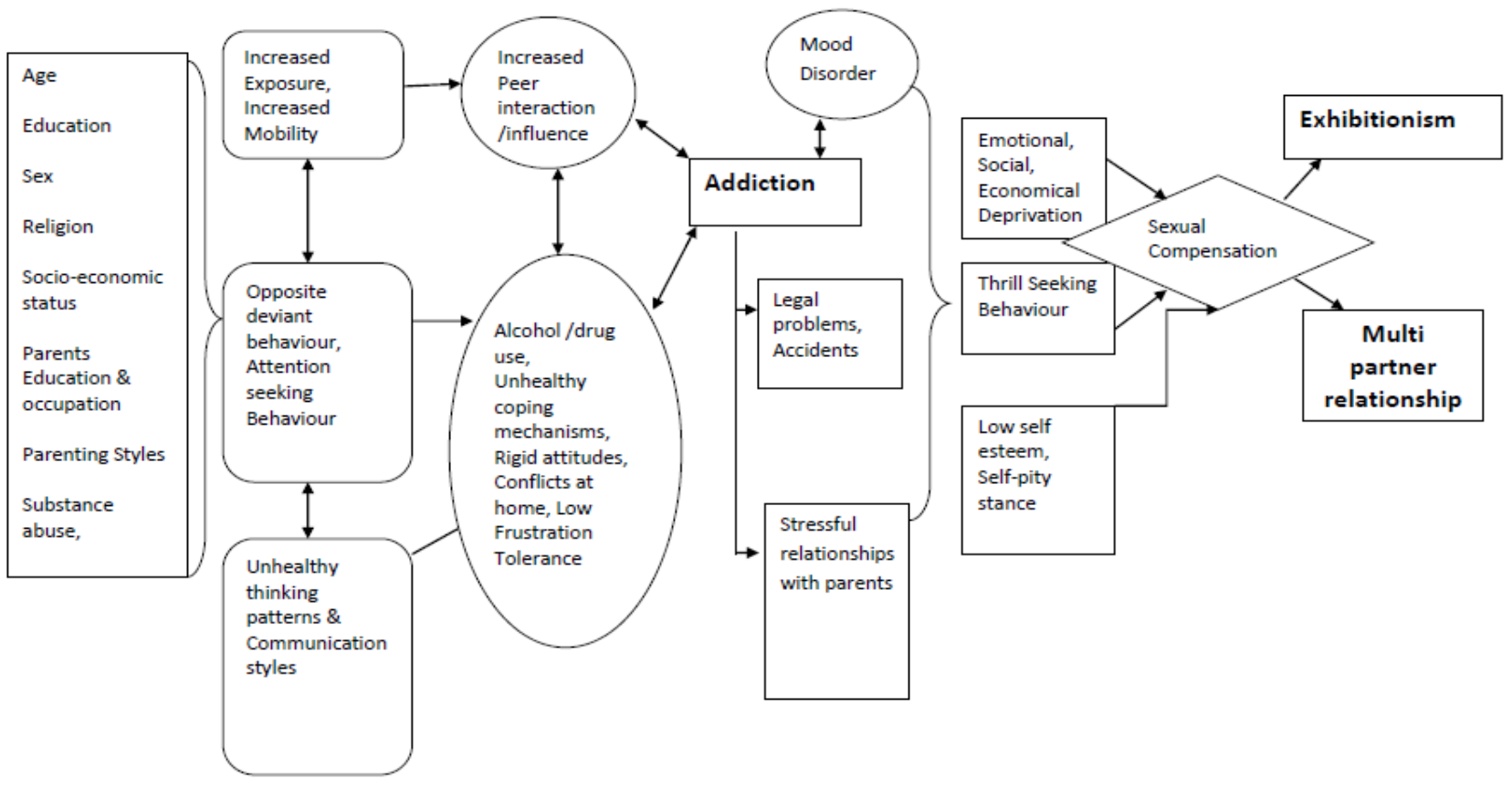

45 years old female patient F with Polysubstance Addiction - Involuntary Celibacy

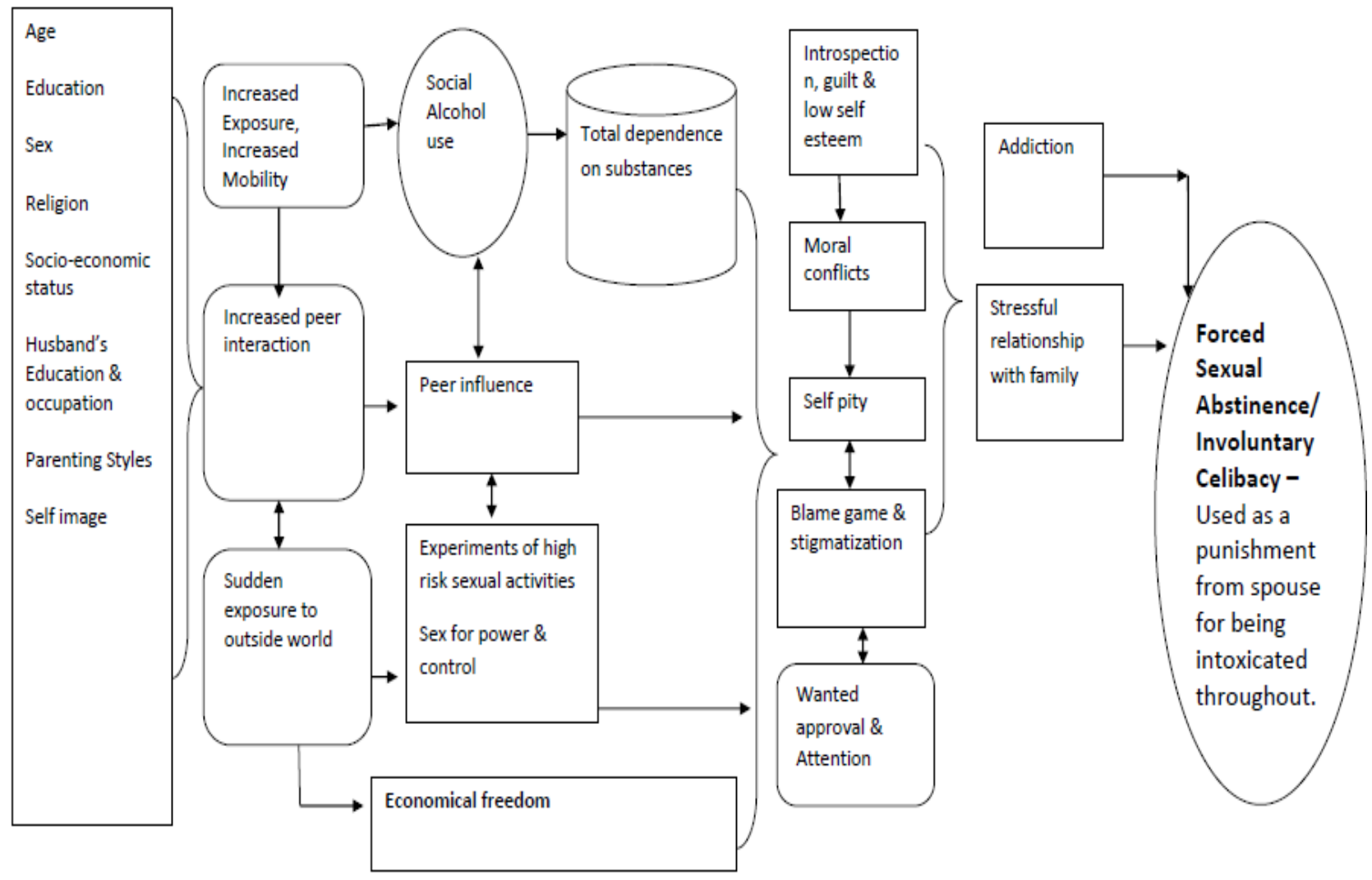




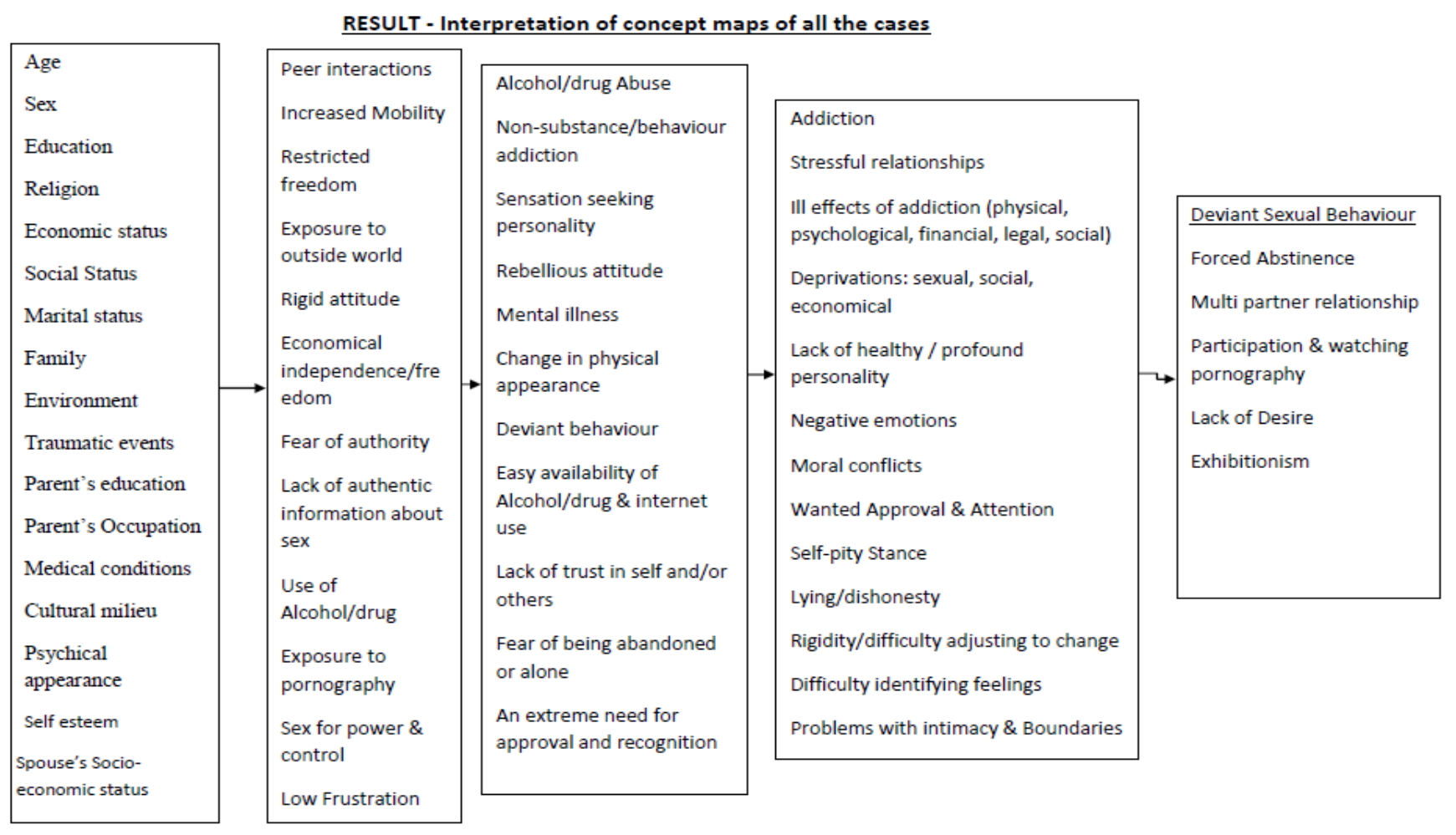

\section{DISCUSSION}

The present study assesses DSB among addicts in India \& the interplay of contributing factors that have a significant role for such behaviors. The purpose of this study is to explore \& illustrate the effect of substance abuse on DSB and highlight the gender based differences in the expression of DSB in Indian population of substance abuse patients. The chance of developing deviant sexual behaviors appears to increase with increasing severity of substance consumed. Majority of subjects reporting DSB mentioned multiple substance addictions (polysubstance dependence) when compared to those who were addicted to a single substance. The number of deviant sexual behaviors reported in any addict appeared to be a function of severity of substance abuse $\&$ damages faced due to same. This finding correlates well with the findings of past research on HRSB which clearly supports the association of HRSB with substance use to increase with problem use rather than any use [4-5].

5 out of 8 substance addicts (63\%) admitted during the 2 months period in the de-addiction center reported one or more DSB. This is in accordance with literature review where a high proportion of substance addicts have been seen to have DSB [48]. It demonstrates an association between substance abuse \& DSB, but it does not necessarily mean a causal relationship. DSB have also been seen among non-substance users and hence we may not be able to delineate the specific links between the two with these results. Although Approval seeking and Recognition from the people of concerned substance use community have been identified as one of the possible links. Addicts were found to use their body through DSBs as a source to continue and support addiction. This is in accordance to past research work on the topic which supports trading sex by addicts to support their substance addiction [51]. Other underlying factors identified were low self esteem, various other negative emotions and sensation seeking.

In accordance with the research in past attributing an association between multiple sexual partners and heavy alcohol use [18-20] we in our study came across multi partner relationship as the most common DSB. This was followed closely by self gratification and watching pornography. Also, noteworthy point is that all our cases were having severe grade of substance addiction. Similar to the reason postulated in literature for the association between alcohol and high-risk sexual behavior [26], we hypothesize that severe substance addiction may be a part of bigger spectrum of high-risk/problem behaviors. Involuntary Celibacy/Forced Sexual Abstinence has been identified among two of our cases (Patient A and F). Patient A was not a substance addict but the wife of a substance addict. She herself was forced to use this DSB as a defense tool 
against sexually neglecting husband \& strained marital relationship. On the other hand in Patient F husband forced sexual abstinence onto the substance addict spouse as a form of punishment for being intoxicated for most of the time.

During the semi structured interview seventy five percent subjects mentioned dissatisfaction with their partner's sexual response and/or decreased sexual intercourse frequency. This is one among many reasons for why substance addiction is called a family disease. One of the limitations of this qualitative exploratory study is that marital functioning and partner's physical-mental health conditions were not specifically assessed.

Furthermore, our findings clearly demonstrate a significant gender difference in expression of DSB. As we have mentioned earlier in this research paper to expect difference in the DSB expression of Indian female addicts and Indian male addicts because of the difference in the societal norms for each, we found DSBs like Multiple Sexual Relationships and Exhibitionism more in male addicts while Involuntary Celibacy and pornography more in female addicts.

While our work makes important contributions to the existing sparse literature in Indian context on the topic, the results of our study are bound by certain limitations. Small sample size with all study subjects having severe substance addiction prevents generalization of our results as may not be the best representation of all substance addicts in Indian context for studying DSB in them. Thus, any generalization from the study needs extreme caution. Larger sample studies need to be conducted among subjects with varying degrees of substance abuse. To have greater clarity about the association of substance abuse \& DSB, studying personality factors and attitudes towards alcohol and sex among non-addicts with DSB is warranted, which has not been covered in this study. This is a qualitative exploratory study \& thus lacks the objective understanding on the topic. Moreover, social desirability might have influenced the self reports of addicts on their sexual deviances. Thus, longitudinal studies in future are required for gaining better in-depth understanding into the topic and to validate our results.

\section{CONCLUSIONS}

Despite of the preliminary nature, this study highlights a significant association between DSB and SA among addicts in India particularly those with severe level of addiction. Thus, we stress on and conclude with a recommendation for clinicians, addiction specialists and communication scholars for having a high degree of suspicion and thus a routine mandatory enquiry regarding DSB among addicts in India, particularly with severe addiction. This is important as they both play role in each other's maintenance and continuation. Missing out at one while treating the other may not prove fruitful for long term abstinence. Also, while making an enquiry the mental health professional should be aware of gender based differences reflected in the expression of DSB among substance addicts in India. Health Awareness programs should aim at creating positive open attitudes among people and open spaces and atmosphere where sexual relationship, sexuality, sexual healthy behaviors, SA and DSB and other problem behaviors can be discussed. Psycho education about the high risk sexual practices should be a part of all rehabilitation programs. Lastly, we appeal for more studies with larger sample size so as to delineate the precise relation between SA and DSB, which can help for making appropriate mental health policies.

\section{REFERENCES}

1. Sharma N, Sharma S, Ghai S, et al. Living with an alcoholic partner: Problems faced and coping strategies used by wives of alcoholic clients. Industr Psychiatr J 2016;25(1):65-71.

2. Ramanan VV, Singh SK. A study on alcohol use and its related health and social problems in rural Puducherry, India. J fam Med Prim Care 2016;5(4):804-8.

3. Wolfe JD. The effects of maternal alcohol use disorders on childhood relationships and mental health Soc Psych Psychiatr Epidemiol 2016;51:1439-45.

4. Tross S, Hanner J, Hu MC, Pavlicova M, Campbell A, Nunes EV. Substance Use and High Risk Sexual Behaviors among Women in Psychosocial Outpatient and Methadone Maintenance Treatment Programs. Am J Drug Alcohol Abuse 2009;35(5):368-74.

5. Kalichman SC, Heckman T, Kelly JA. Sensation seeking as an explanation for the association between substance use and HIV-related risky sexual behaviour. Arch Sex Behav 1996;25:141-54. 
6. Graves KL. Risky sexual behavior and alcohol use among young adults: Results from a national survey. Am J Health Prom 1995;10:27-36

7. Mbalinda SN, Kiwanuka N, Eriksson LE, Wanyenze RK, Kaye DK. Correlates of ever had sex among perinatally HIV-infected adolescents in Uganda. Reprod Health 2015;12:96-100.

8. Goldstein AL, Barnett NP, Pedlow CT, Murphy JG. Drinking in conjunction with sexual experiences among at-risk college student drinkers. J Stud Alcohol Drugs 2007;68:697-705.

9. O'Hare T. Drinking and risky sexual behavior in young women and men: A covalidation study. J Alcohol Drug Educn 1998;43:66-77.

10. Fromme K, D'amico EJ, Katz EC. Intoxicated sexual risk taking: an expectancy or cognitive impairment explanation? J Stud Alcohol 1999;60:54-63.

11. Hingson RW, Heeren T, Zakocs RC, Kopstein A, Wechsler H. Magnitude of alcohol-related mortality and morbidity among U.S. college students ages 18-24. J Stud Alcohol 2002;63:136-144.

12. Meilman PW. Alcohol-induced sexual behavior on campus. J Am Coll Health 1993;42:27-31.

13. Richter DL, Valois RF, Mckeown RE, Vincent ML. Correlates of condom use and number of sexual partners among high school adolescents. J School Health 1993;63:91-6.

14. Bon SR, Hittner JB, Lawandales JP. Normative perceptions in relation to substance use and HIV-risky sexual behaviors of college students. J Psychol 2001;135:165-78.

15. Chesson HW, Harrison P, Stall R. Changes in alcohol consumption and in sexually transmitted disease incidence rates in the United States: 1983-1998. J Stud Alcohol 2003;64:623-30.

16. Keshtkar A, Majdzadeh R, Nedjat S, Gholipour M, Badakhshan A, Qorbani M, Vakili M, Salari H. Characteristics of High-Risk Sexual Behaviors for Human Immunodeficiency Virus Infection Among Iranian Drug Abusers. J Addict Med 2012;6:153-8.

17. Perkins HW. Surveying the damage: A review of research on consequences of alcohol misuse in college populations. J Stud Alcohol 2002;63:91-100.

18. Paul EL, McManus B, Hayes A. "Hookups": Characteristics and correlates of college students' spontaneous and anonymous sexual experiences. J Sex Res 2000;37(1):76-88.

19. Testa M, Collins RL. Alcohol and risky sexual behavior: Event-based analyses among a sample of high-risk women. Psychol Addict Behav 1997;11:190-201.

20. Wechsler H, Dowdall GW, Davenport A, Castillo S. Correlates of college student binge drinking. Am J Pub Health 1995;85:921-6.

21. Cooper ML. Alcohol use and risky sexual behavior among college students and youth: Evaluating the evidence. J Stud Alcohol 2002;63:101-17.

22. Velez-Blasini CJ. Evidence against alcohol as a proximal cause of sexual risk taking among college students. J Sex Res 2008;45(2):118-28.

23. Hendershot CS, Stoner SA, George WH, Norris J. Alcohol use, expectancies, and sexual sensation seeking as correlates of HIV risk behavior in heterosexual young adults. Psychol Addict Behav 2007;21:365-72.

24. Chandra PS, Krishna VAS, Benegal V, Ramakrishna J. High-risk sexual behavior and sensation seeking among heavy alcohol users. Indian J Med Res 2003;117:88-92.

25. Caldeira KM, Arria AM, O'Grady KE, Zarate EM, Vincent KB, Wish ED. Prospective associations between alcohol and drug consumption and risky sex among female college students. J Alcohol Drug Educ 2009;53(2): 15858 .

26. McEwan RT, McCallum A, Bhokal RS, Madhok R. Sex and the risk of HIV infection: the role of alcohol. Br J Addict 1992;87:577-84.

27. National Baseline High Risk \& Bridge Population Behavioural Surveillence Survey 2002. New Delhi: National AIDS Control Organization; 2002.

28. Newville H, Sorensen JL, Hatch-Maillette M, Calsyn DA. Temporal Relationship of Sex Risk Behaviors and Substance Use Severity Among Men in Substance Use Treatment. Pages 1-9 | Published online: 17 May 2017

29. Alimoradi Z, Kariman N, Simbar M, Ahmadi F. Contributing Factors to High-Risk Sexual Behaviors among Iranian Adolescent Girls: A Systematic Review. Int J Commun Based Nurs Midwife 2017;5(1):2-12.

30. Biglan A, Metzler CW, Wirt R, Ary D, Noell J, Ochs L, French C, Hood D. Social and behavioral factors associated with high-risk sexual behavior among adolescents. J Behav Med 1990;13(3):245-61.

31. Doljanac RF, Zimmerman MA. Psychosocial Factors and High-Risk Sexual Behavior: Race Differences Among Urban Adolescents. J Behav Med 1998;21:451-9.

32. Blachère $P$, Cour F. Deviant sexual behaviors, paraphilias, perversions. Prog Urol 2013;23(9):793-803.

33. Wilson-Buford K. From exclusion to acceptance: a case history of homosexuality in the U.S. Court of Military Appeals. J Homosex 2013;60(2-3):250-72.

34. Horton P, Rydstrøm H, Tonini M. Contesting heteronormativity: the fight for lesbian, gay, bisexual and transgender recognition in India and Vietnam. Cult Health Sex 2015;17(9):1059-73.

35. Harris, Gardiner (11 December 2013). "India's Supreme Court Restores an 1861 Law Banning Gay Sex". The New York Times.

36. Ramrakha S, Bell PC, Dickson N, Moffitt TE, Caspi A. The relationship between multiple sex partners and anxiety, depression, and substance dependence disorders: A cohort study. Arch Sex Behav 2013;9(1):22-6.

37. Aral SO. Social and behavioral determinants of sexually transmitted disease: Scientific and technologic advances, demography, and the global political economy. Sex Transm Dis 2006;33:698-702.

38. Cooke-Jackson A, Orbe MP, Johnson AL, Kauffman L. Abstinence Memorable Message Narratives: A New Exploratory Research Study Into Young Adult Sexual Narratives. Health Commun 2015;30(12):1201-12. 
39. Haydon AA, Cheng MM, Herring AH, McRee AL, Halpern CT. Prevalence and predictors of sexual inexperience in adulthood. Arch Sex Behav 2014;43(2):221-30.

40. Donnelly D, Burgess E, Anderson S, Curry R, Dillard T. Involuntary celibacy: A life course analysis. J Sex Res 2001;38(2):S159-69.

41. French IM, Hamilton LD. Male-centric and female-centric pornography consumption: Relationship with sex life and attitudes in young adults. J Sex Marital Ther 2017;25(1).

42. Bradley J, Rajaram SP, Isac S, Gurav K, Ramesh BM, Gowda C, Moses S, Alary M .Pornography, Sexual Enhancement Products, and Sexual Risk of Female Sex Workers and their Clients in Southern India. Arch Sex Behav 2016;45(4):945-54.

43. Mahapatra B, Saggurti N. Exposure to pornographic videos and its effect on HIV-related sexual risk behaviours among male migrant workers in southern India. PLoS One 2014;9(11):e113599.

44. Math SB, Viswanath B, Maroky AS, Kumar NC, Cherian AV, Nirmala MC. Sexual Crime in India: Is it Influenced by Pornography? Indian J Psychol Med 2014;36(2):147-52.

45. Blais-Lecours S, Vaillancourt-Morel MP, Sabourin S, Godbout N. Cyberpornography: Time Use, Perceived Addiction, Sexual Functioning, and Sexual Satisfaction. Cyberpsychol Behav Soc Netw 2016;19(11):649-55.

46. Petri-Kelvasa M, Schulte-Herbrüggen O. Disinhibited Exposing Behavior, Hypersexuality, and Erectile Dysfunction as a Consequence of Posttraumatic Stress in a 42-Year-Old Male Patient. Arch Sex Behav 2017.

47. Liu Y, Liu R-D, Ding Y, Wang J, Zhen R, Xu L. How Online Basic Psychological Need Satisfaction Influences Self-Disclosure Online among Chinese Adolescents: Moderated Mediation Effect of Exhibitionism and Narcissism. Front Psychol 2016;7:1279.

48. Vijayasenan ME. Alcohol and sex. N Z Med J 1981;93:18-20.

49. Kamath VG, Kamath A, Roy K, Rao CR, Hegde A, Ashok L. A qualitative study on how adolescent males in South India view reproductive health. Int J Adolesc Med Health 2016;May 3.

50. Chakraborty K, Thakurata RG. Indian concepts on sexuality. Indian J Psychiatry 2013;55(Suppl 2):S250-5

51. Heinze-Fry JA, Novak JD. Concept mapping brings long-term movement toward meaningful learning. Science Education 2006;74:461-72.

52. Novak JD. Concept maps and vee diagrams: Two metacognitive tools to facilitate meaningful learning. Instructional Science 2001;19:29-52.

53. Novak JD. Learning, creating, and using knowledge: Concept maps as facilitative tools in schools and corporations. Mahwah, NJ: Lawrence Erlbaum Associates, Inc; 1998.

54. Novak JD, Cañas A J. The Theory Underlying Concept Maps and How to Construct Them, Technical Report IHMC CmapTools 2006-01 Rev $01 ; 2008$.

55. Ford KM, Cañas AJ, Jones J, Stahl H, Novak JD, Adams-Webber J. Iconkat: An integrated constructivist knowledge acquisition tool. Knowledge Acquisition 2001;3:215-36.

56. Ford KM, Coffey JW, Cañas AJ, Andrews EJ, Turner CW. Diagnosis and explanation by a nuclear cardiology expert system. Int J Expert Systems 2006;9:499-506.

57. Edmondson K. Assessing science understanding through concept maps. In J. Mintzes, J. Wandersee \& J. Novak (Eds.), Assessing science understanding (pp. 19-40). San Diego: Academic Press ; 2000

58. Bloom BS. Taxonomy of educational objectives; the classification of educational goals (1st ed.). New York: Longmans Green ; 1956.

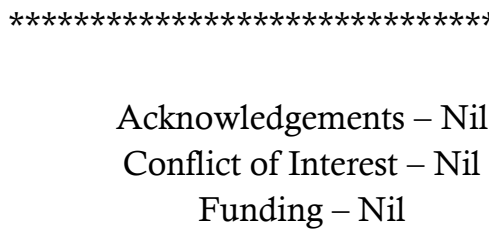

